\title{
NUMERICAL CALCULATION OF INTERNAL INDUCED FIELDS IN HUMANS DUE TO HIGH VOLTAGE TRANSMISSION LINES
}

\author{
G. A. KULKARNI*, W. Z. GANDHARE** \\ *Department of Electrical Engineering, Research Scholar, \\ Govt. College of Engineering, Aurangabad, India, tel. +91 9970052498, e-mail: girish227252@ rediffmail.com \\ ** Principal, Govt. College of Engineering, Amravati, India, tel. +91 9822658374, \\ e-mail: wz_gandhare@yahoo.co.in
}

\begin{abstract}
Interaction of extremely low frequency (ELF) electromagnetic fields (EMF) with human has been a great concern over the previous years for researchers. ELF EMFs emanating from high voltage transmission lines interact with human by inducing electric fields internally in body. Various studies have shown the ill effects of this interaction on human organism. In this paper, numerical calculations of internally induced electric field and current density in human of different gender and age are done. Maximum values of external electric and magnetic fields are estimated from the detailed survey carried out on $132 \mathrm{kV}$ high voltage transmission line. Human body is a complex structure comprising of several tissues with varying values of conductivity and relative permittivity. It is very difficult to describe the interaction of external fields with every single tissue and no direct method is available for measurement of internally induced fields. Internal fields are estimated with the help of homogeneous ellipsoid model. The total induced electric field and current density due to combined effect of external electric and magnetic field is calculated. Results obtained are compared with recommended exposure levels.
\end{abstract}

Keywords: Extremely Low Frequency, Electromagnetic Fields, Human Body, Health Effects, High Voltage Transmission Lines, Ellipsoid

\section{INTRODUCTION}

Overhead high voltage transmission lines are the major source which produces manmade extremely low frequency (ELF) electromagnetic fields. Along with natural ELF EMF these manmade fields also falls under the category of non ionizing radiations. Exposure to alternating electric and magnetic fields induce electric fields inside the human bodies. The magnitude of internally generated fields is different for external electric and magnetic fields. Their magnitude also depends upon varying values of dielectric properties of complex human body organs. The distribution of the internal fields induced by these two types of fields is different, but at cellular level no fundamental difference was observed [1]. Interaction of internal fields with human body can produce certain biological variations. The very first association between ELF exposure and human health was shown in 1979, which associated increased risk of childhood leukemia to persons living near power lines [2]. Since then huge studies were conducted to determine the biological effects of occupational and residential exposure. Certain studies have shown the positive association of health effects and ELF exposure. The International Agency for Research on Cancer (IARC) has classified ELF magnetic fields as, "Possibly Carcinogenic to Humans" [3-4]. International organizations like IEEE, international commission on non ionizing radiation and protection (ICNIRP) has recommended certain limits for these exposures. For controlled environment external exposure limit for electric field is 20 to $25 \mathrm{kV} / \mathrm{m}$ and for magnetic field it is $1 \mathrm{mT}$ to $2.71 \mathrm{mT}$. General public exposure limit is $5 \mathrm{kV} / \mathrm{m}$ to $12 \mathrm{kV} / \mathrm{m}$ for electric field whereas it is $0.1 \mathrm{mT}$ to $1.6 \mathrm{mT}$ for external magnetic field. However levels of ELF fields beyond certain limit may result in harmful effects. Various analytical and numerical methods have been developed in previous years to determine the internally induced fields. Internal distribution of induced fields in various organs can be observed by the realistic developed model of human body. Numerical methods along with human body models allow minute simulations of low frequency dosimetry considering exposure to low frequency EMF sources. Various numerical methods have been used for such simulations, including finite element methods (FEM), integral equation (IE) methods, finite difference (FD) techniques, the impedance method, finite difference time domain (FDTD) methods, and inverse admittance methods [5].These highly sophisticated numerical methods are used for internal field calculations along with simplified human body models with varying values of dielectric properties [6-9]. Some dosimetry computations represent the human body using various geometric shapes with single conductivity value for calculations [10-15]. In these studies, the electromagnetic fields impacts on the people staying near the high voltage transmission lines have been examined. The results of these studies motivated the author to look for relationship between exposure to electric and magnetic field from high voltage transmission lines and its effects on human beings.

In this paper exposure assessment was carried out around $132 \mathrm{kV}, 50 \mathrm{~Hz}$ high voltage transmission line. The reason of selecting this particular line is that, it is one of the most common transmission lines passing near to the roads, fields and other utilities. It has been observed that even after recommended regulations there is ample growth of residential colonies in proximity to these lines. This safety assessment study is a small step to provide information to peoples in close proximity, health workers and regulatory agencies. Measurement results of induced electric fields and current densities due to the external electromagnetic fields around $132 \mathrm{kV}$ power transmission 
line are presented here. Dual Function - Gauss/Tesla meter was used for measurement of external fields. Internal fields were calculated with the help of ellipsoid human body models.

The paper is organized as follows; initial part discusses the recommended exposure limits, measurement of external fields and site selected for measurement followed by ellipsoid human body model and internal field calculations. The last part deals with result and finally conclusions are drawn.

\section{EXTERNAL ELECTROMAGNETIC ENVIRONMENT}

Assessing impact of external electromagnetic fields around $132 \mathrm{kV}$ lines deals with reviewing the limits set by various organizations for external exposure and site selection with external field measurements.

\subsection{External Exposure Limits}

Exposure of electromagnetic fields on biological matter at extremely low frequency is the prime concern for determining the safe levels. As a result of cumulative research on interaction issue, many international organizations have developed guidelines and safe standards for such permissible exposure levels. Maximum exposure limit of electric field for controlled environment and general public normally range from 10 to $25 \mathrm{kV} / \mathrm{m}$ and 5 to $12 \mathrm{kV} / \mathrm{m}$ respectively [16]. Magnetic field exposure limits range between 0.5 to $2.71 \mathrm{mT}$ for controlled environment and 0.1 to $1.6 \mathrm{mT}$ for general public. Summary of exposure limits is given in table I. The purpose of this tabular data is to compare the maximum values of electric and magnetic fields obtained during survey with said exposure limits.

Table 1 Summary of external exposure limits from different regulating organizations [16]

\begin{tabular}{|c|c|c|c|}
\hline $\begin{array}{c}\text { Organiz } \\
\text { ation }\end{array}$ & Field & $\begin{array}{l}\text { Controlled } \\
\text { Environment }\end{array}$ & $\begin{array}{l}\text { General } \\
\text { Public }\end{array}$ \\
\hline \multirow{2}{*}{ IEEE } & $\begin{array}{c}\text { Electric } \\
\text { Field }(\mathrm{kV} / \mathrm{m})\end{array}$ & 20 & 5 \\
\hline & $\begin{array}{c}\text { Magnetic } \\
\text { Field }(\mathrm{mT})\end{array}$ & $\begin{array}{l}2.71 \text { (Head } \\
\text { and Torso) }\end{array}$ & $\begin{array}{c}0.904 \text { (Head } \\
\text { and Torso) }\end{array}$ \\
\hline \multirow{2}{*}{ ICNIRP } & $\begin{array}{c}\text { Electric } \\
\text { Field }(\mathrm{kV} / \mathrm{m})\end{array}$ & 10 & 5 \\
\hline & $\begin{array}{c}\text { Magnetic } \\
\text { Field }(\mathrm{mT})\end{array}$ & 0.5 & 0.1 \\
\hline \multirow{2}{*}{ NRPB } & $\begin{array}{c}\text { Electric } \\
\text { Field }(\mathrm{kV} / \mathrm{m})\end{array}$ & 12 & 12 \\
\hline & $\begin{array}{l}\text { Magnetic } \\
\text { Field (mT) }\end{array}$ & 1.6 & 1.6 \\
\hline \multirow{2}{*}{ ACGIH } & $\begin{array}{c}\text { Electric } \\
\text { Field }(\mathrm{kV} / \mathrm{m})\end{array}$ & 25 & N.A. \\
\hline & $\begin{array}{l}\text { Magnetic } \\
\text { Field (mT) }\end{array}$ & 1 & N.A. \\
\hline
\end{tabular}

\subsection{Problem Formulation}

The living organisms, in close proximity to high voltage transmission lines are exposed to ELF electromagnetic fields. Interaction of ELF fields with living organisms and their biological effects is a matter of research with expansion in electric power generation, transmission and distribution network. As a first step towards establishing a link to determine the exact mechanism of such interaction, external electromagnetic fields are to be measured.

High voltage transmission lines are usually found along highways. Peoples passing/residing in close proximity to high voltage transmission lines and hotline workers are the two major community sections which experiences exposure to ELF electromagnetic fields. Hotline workers are quite aware about the facts and safeguards relating to exposure issue. Common community members usually have belief that electricity can be fatal only upon direct contact. However, occupational and residential exposure to ELF fields can be a matter of human health without physical contact with high voltage transmission lines. Various countries have already established standards for minimum safe clearance between power lines and any type of establishments. This distance depends on the voltage of the power line. Importance of this distance is that the strength of these fields diminishes rapidly with distance from source. The recommended distance for $132 \mathrm{kV}$ line is about 15 to $20 \mathrm{~m}$ [17-18]. However there are several reports were published indicating possible link between exposure to ELF and leukemia [19], miscarriage risk [20] and neurodegenerative diseases [21] even with a greater distance than recommended one.

To our knowledge, majority of the studies related to proximity effects were applied to hotline workers and maintenance persons. The study report conducted by Department of Health of Republic of South Africa [22], have classified human population, which experiences exposure in two types. One is the occupationally exposed population which consists of adults who are generally exposed to EMF under known conditions during the normal course of their particular employment. This group is trained to be aware of the potential risk and to take appropriate precautions. While the second group is of general public, this comprises individuals of all ages and of varying health status and may include particularly susceptible groups or individuals. In many cases, members of the public are unaware of their exposure to EMF. Moreover, individual members of the public cannot reasonably be expected to take precautions to minimize or avoid exposure [22]. These considerations caused the author to formulate the problem with calculation of induced internal fields in humans which experiences residential exposure from $132 \mathrm{kV}$ lines. The detailed literature review with concerned topic raised some questions concerning the geographical location in which community member's experiences long time exposure. The present study analyses:

a) The levels of external and internal exposure in people residing in close proximity to high voltage transmission lines.

b) Variation in levels of these fields for different gender and age.

c) The level of fields when the recommended minimum safe clearance is overcome. 
Datasets generated at the end of the study will also help to understand about the intensity of these fields outside and inside the human body. Values of fields obtained during the study can further be used to investigate the direct and indirect effects of ELF EMF fields on other species along with humans.

\subsection{Field Measurements}

To conduct study on proximity effects, a double circuit high voltage transmission line was selected. This line spans from Deepnagar to Pachora in Jalgaon region of Maharashtra, India. We have scanned the entire area through which this line passes and finally selected a colony, which is built on both sides in close proximity to the transmission line. The houses are built parallel to the transmission line. This site is the best example where community members are exposed to ELF EMF, while performing their daily routine.

The selected line ran East-West. External field measurements were carried out at six different scenarios. At every 5 meters along the span, 5, 10 and 15 meters to the North of the span and 5, 10 and 15 meters to the South of the span. The measurement locations were all along the same perpendicular crossing the transmission line.

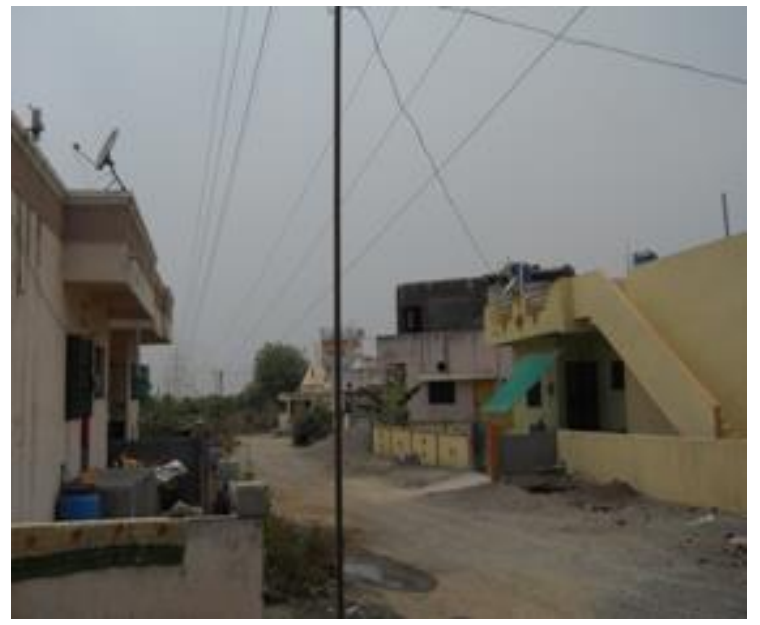

Fig. 1 Selected Site for Measurement of Electromagnetic Field

External field measurements were conducted using ME3830B [23]. It is a dual function Gauss/ Tesla meter for AC electric and magnetic fields. This meter allows evaluation of the exposure caused by $\mathrm{AC}$ electric and magnetic fields based on standard measurement procedures and protocol recommended by IEEE. Four sets of readings were generated at the targeted locations consecutively at different period of time. The time slots selected were based on load conditions. The readings were recorded at an interval of $6 \mathrm{Hrs}$, starting from 6:00 am to 12:00 pm. The criterion for selecting the time slots was related to electricity consumption by general consumers and industries. The purpose of taking multiple readings was to improve reliability of readings with respect to daily load variations. Maximum readings out of above sets were considered for further calculations. The electric and magnetic field values were maximum during first time slot (6:00 am to 12:00 noon). The electric field strength obtained was varying from 0.317 to $1.947 \mathrm{kV} / \mathrm{m}$ whereas magnetic field strength varying between 912 to $1780 \mathrm{nT}$. The maximum values for both the quantities are at a distance of $170 \mathrm{~m}(\mathrm{sag})$

\section{INTERNAL INDUCED FIELDS}

Induction of internal fields in biological bodies due to interaction with the external electric and magnetic fields is of great concern since last few years. This part of the paper deals with analyzing the internal induced fields in humans.

\subsection{Body Modeling}

There are no direct techniques available to calculate the internally induced fields in human body so various indirect techniques are used. Here analysis of whole body exposure to ELF EMF emanating from $132 \mathrm{kV} \mathrm{HV}$ transmission line is done. Homogeneous adult shaped ellipsoid models are used for the same.

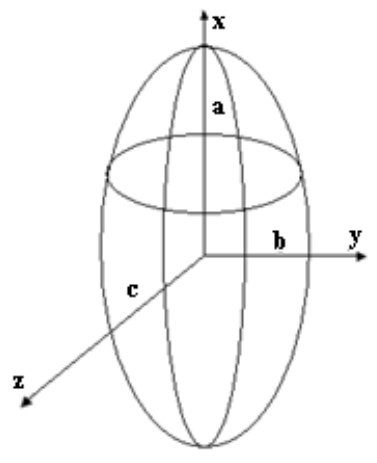

Fig. 2 Ellipsoid Body Model

In close proximity to a $\mathrm{HV}$ transmission line the internal induced electric field in conducting object is given by [1],

$J=\sigma \times E$

$E_{T}=E_{e}+E_{m a g}$

Where: $E_{T}$ - Total induced electric field, $E_{e^{-}}$Internal electric field due to external electric field, $E_{m a g}$ - Internal electric field due to external magnetic field.

Spheres, prolate spheroids, cylinder and rectangular solids are analytical models widely used to represent living organisms under ELF exposure conditions. As a tool for calculation of internal induced field studies each of these models is useful. However because of the generality, relative morphological realism and ability to provide solution in closed form ellipsoid model is the best alternative [15]. It is relatively simple and widely used technique for dosimetry related studies. This paper presents calculations of internal fields based on mathematical model comprising of an ellipsoid representing various size and shape of the body. Ellipsoid parameters for different age groups were considered [24] which are given in table II. Effects of external electric and magnetic field on biological bodies are the two separate issues in terms of interaction. So, two separate approaches were used to find their effects. 
Table 2 Ellipsoid Parameters for Selected Human Models

$\begin{array}{cccc}\text { Selected Models } & a & b & c \\ \text { Average Man } & 0.875 & 0.195 & 0.098 \\ \text { Average Women } & 0.805 & 0.2 & 0.091 \\ \text { Average Endomorphic } & 0.88 & 0.225 & 0.17 \\ \text { (fat) man } & & & \end{array}$

\subsection{Internal Field Calculations}

\section{2.a. Electric Field}

The relationship between the external undisturbed electrical field strength $E_{O}$ and the electrical field strength induced in the body tissue $E_{e}$ for ellipsoid model is expressed by [25],

$$
E_{e}=\frac{k \times 2 \times \pi \times f \times \varepsilon_{O}}{\sigma} \times E_{O}
$$

Where: $k$ - Field distortion factor, for Human beings $(k=13-18), \varepsilon_{o}$ - permittivity of free space (vaccum).

$$
\varepsilon_{O}=\frac{1}{\mu_{O} \times c_{O}^{2}}=8.854 \times 10^{-12} \frac{A^{2} \times s^{4}}{k g \times m^{2}}
$$

Where: $f$ - frequency of the exposed Field, $\sigma$ Conductivity of tissue.

As human body is a complex structure, conductivity of different tissue is varying between 0.0002 to 2 . In simple models the Human body can be treated as homogeneous taking conductivity of the tissue as $0.15 \mathrm{~S} / \mathrm{m}$ [26].

By using equations (1) and (3) internal induced current density due to the electric field was found.

\section{2.b. Magnetic Field}

The standard equation of an ellipsoid is,

$$
\frac{x^{2}}{a^{2}}+\frac{y^{2}}{b^{2}}+\frac{z^{2}}{c^{2}}=1
$$

Where $x, y$ and $z$ are rectangular coordinates and $a, b$ and $c$ indicates the shape and size of the ellipsoid.

In human ellipsoid model the body parameter i.e. height, width and depth are defined by $2 a, 2 b$ and $2 c$ respectively.

Considering magnetic field aligned to $\mathrm{x}$-axis, the induced electric filed (Emag) in y-z plane can be given as,

$$
\begin{aligned}
& E_{\text {mag }}=\frac{\omega \times \beta_{O}}{\sqrt{5}} \times \frac{b \times c}{\sqrt{b^{2}+c^{2}}} \\
& E_{\text {mag }}=\frac{2 \times \pi \times f \times \beta_{O}}{\sqrt{5}} \times \frac{b \times c}{\sqrt{b^{2}+c^{2}}}
\end{aligned}
$$

Where: $\beta_{O^{-}}$is magnetic field.

From equations (1) and (6) internal induced current density due to magnetic field was found.

\section{RESULTS}

Calculation of internally induced fields needs the values of external fields in electromagnetic environment of $132 \mathrm{kV}$ line. A detailed field survey was carried out along transmission line to generate this dataset. External Field measurements were performed at an interval of 5 meters along the span for six different scenarios.

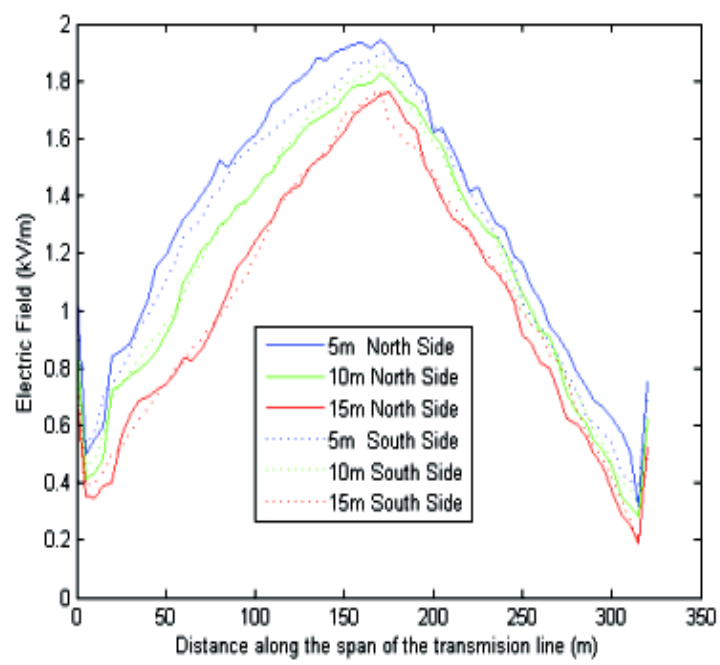

Fig. 3 Graph of Measured Values of Electric Field

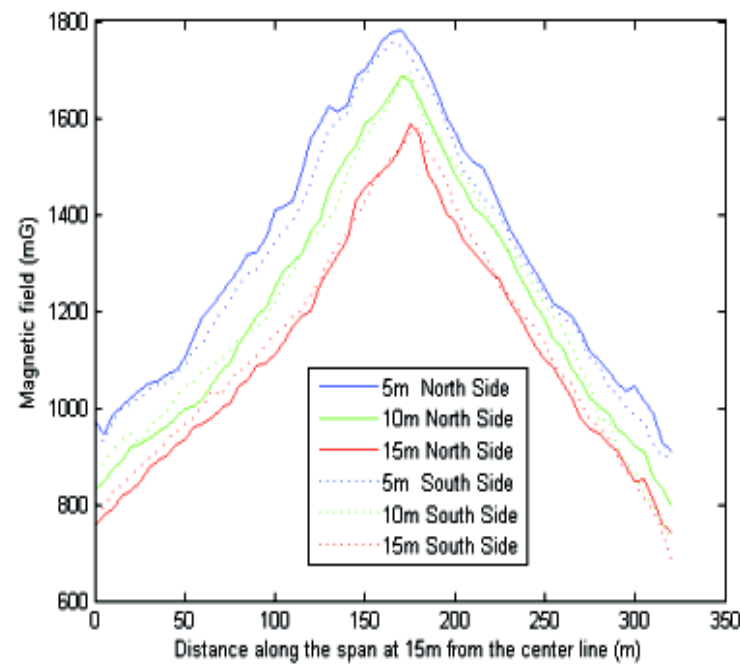

Fig. 4 Graph of Measured Values of Magnetic Field

Figure 3 and 4 shows the values of fields in external electromagnetic environment. There is significant variation in electric and magnetic field strength with respect to change in distance from the line. The graph shows the electric and magnetic fields strength increases as we move towards the line and reduces as we move away from the line. Maximum values obtained out of the generated dataset are taken for internal field calculations.

Table III shows the maximum values obtained for above six cases. Maximum values considered for internal field calculations are $1.947 \mathrm{kV} / \mathrm{m}$ and $1780 \mathrm{nT}$ for magnetic field obtained in scenario I. 
Table 3 Maximum values of Electric and Magnetic fields obtained for six different scenarios

$\begin{array}{ccc}\text { Scenario } & \text { Max. Electric } & \text { Max. Magnetic } \\ & \text { Field }(\mathrm{kV} / \mathrm{m}) & \text { Field }(\mathrm{nT}) \\ \text { I } & 1.947 & 1780 \\ \text { II } & 1.827 & 1685 \\ \text { III } & 1.763 & 1586 \\ \text { IV } & 1.905 & 1756 \\ \text { V } & 1.863 & 1695 \\ \text { VI } & 1.765 & 1579\end{array}$

These values were taken as a worst case scenario along the span, for the calculation of the internal electric field and current densities induced internally in the human body using ellipsoid model.

The induced electric fields and current densities due to external electromagnetic fields are given in tables IV-VI.

Table 4 Internal Induced Electric Field and Current Density due to External Electric Field of $1.947 \mathrm{kV} / \mathrm{m}$

$\begin{array}{ccc}\text { Models } & E_{e}(\mathrm{mV} / \mathrm{m}) & J_{e}(\mathrm{~mA} / \mathrm{m} 2) \\ \text { All } & 0.5773 & 0.08660\end{array}$

Table 5 Internal Induced Electric Field and Current Density due to External Magnetic Field of 1780 nT

$\begin{array}{ccc}\text { Models } & E_{\text {mag }}(\mathrm{mV} / \mathrm{m}) & J_{\text {mag }}(\mu \mathrm{A} / \mathrm{m} 2) \\ \text { Average Man } & 0.0218 & 3.28 \\ \text { Average Women } & 0.0207 & 3.10 \\ \text { Average Endomorphic } & 0.0339 & 5.08\end{array}$

(fat) man

Table 6 Total Internal Induced Electric Field and Current Density due to Combined Effect of External Electric and Magnetic Field

$\begin{array}{ccc}\text { Models } & E_{T}(\mathrm{mV} / \mathrm{m}) & J_{T}(\mathrm{~mA} / \mathrm{m} 2) \\ \text { Average Man } & 0.599 & 0.0898 \\ \text { Average Women } & 0.598 & 0.0897 \\ \text { Average Endomorphic } & 0.611 & 0.0916\end{array}$

(fat) man

\section{CONCLUSIONS}

All the measured values of external electric and magnetic fields are below the recommended limits and can be considered to be at safe clearance level. Using simple coefficients and equations induced internal current densities in whole body for different body sizes is calculated. The induced current densities were calculated for the maximum values of external electric and magnetic fields, measured at the point of sag of $132 \mathrm{kV}$ transmission line. The calculation results show that the internal measured quantities are also well below the recommended exposure levels by various organizations. However internal current density due to external electric field is 20 times more than that of internal current density due to external magnetic field. Apart from that total current density is highest ( $\%$ as compared to all) for a person with round body and high proportion of fat among all age groups. So effect due to electric field and proportion of fat in human body can be the point of attention in near future. Even though these fields are well below the recommended limits as far as direct effect on human body organs is considered, next step of this research will be to analyze whether such low fields below $132 \mathrm{kV}$ lines initiates a biochemical disorder in humans which leads to indirect effects such as anxiety and sleep disorders etc.

\section{REFERENCES}

[1] ANDERSON, L. E. - KAUNE, W. T.: Electric and magnetic fields at extremely low frequencies, In M.J. Suess. Ed., Nonionizing Radiation Protection, $2 \mathrm{~d}$ ed, World Health Organization, Geneva, pp. 175-243, 1989.

[2] WERTHEIMER, N. - LEEPER, E.: Electrical wiring configurations and childhood cancer, Am J Epidemiol, vol. 109(3), pp. 273-284, 1979.

[3] IARC Working Group on the Evaluation of Carcinogenic Risks to Humans, Non-ionizing radiation, Part 1: Static and Extremely LowFrequency (ELF) Electric and Magnetic Fields, Lyon, IARC, 2002 (Monographs on the Evaluation of Carcinogenic Risks to Humans, 80).

[4] Government of Canada, Ministry of Health Catalogue: H 13-7/70-2012, Health Canada Fact Sheet, ISBN: 978-1-100-25395-8.

[5] IEEE StdC95.3.1-2010, IEEE Recommended Practice for Measuements and Computations of Electric, Magnetic, and Electromagnetic Fields with Respect to Human Exposure to Such Fields, $0 \mathrm{~Hz}$ to $100 \mathrm{kHz}$, pp. 45.

[6] CHEN, K. M. - CHUANG, H. R. - LIN, C. J.: Quantification of interaction between ELF-LF electric fields and human bodies, IEEE Trans Biomed Eng, vol. 33(8), pp. 746-756, 1986.

[7] CHIBA, A.: Application of finite element method to analysis of induced current densities inside human model exposed to $60-\mathrm{Hz}$ electric field, IEEE Trans Power Apparatus Systems, vol. 103, pp. 1895-1902, 1984.

[8] DIMBYLOW, P. J.: Finite difference calculations of current densities in a homogeneous model of a man exposed to extremely low frequency electric fields, Bioelectromagnetics, vol. 8, pp. 355-375, 1987.

[9] SPIEGEL, R. J.: Numerical determination of induced currents in humans and baboons exposed to $60 \mathrm{~Hz}$ electric fields, IEEE Trans Electromagnetic Compatibility, vol. 23, pp. 382-390, 1981.

[10] SHIAU, Y. - VALENTINO, A. R.: ELF electric field coupling to dielectric spheroidal models of biological objects, IEEE Trans Biomed Eng, vol. 28(6), pp. 429-437, 1981. 
[11] KAUNE, W. T. - MCCREARY, F. A.: Numerical calculation and measurement of $60-\mathrm{Hz}$ current densities induced in an upright grounded cylinder, Bioelectromagnetics, vol. 6(3), pp. 209-220, 1985.

[12] TENFORDE, T. S. - KAUNE, W. T.: Interaction of extremely low frequency electric and magnetic fields with humans, Health Physics, vol. 53(6), pp. 585606, 1987.

[13] SPIEGEL, R. J.: High-voltage electric field coupling to humans using moment method techniques, IEEE Trans Biomed Eng, BME-24, pp. 466-472, 1977.

[14] FOSTER, K. R. - SCHWAN, H. P.: Dielectric properties of tissues and biological materials: a critical review, Crit Rev Biomed Eng, vol. 17(1), pp. 25-104, 1989.

[15] HART, F. X.: Numerical and analytical methods to determine the current density distributions produced in human and rat models by electric and magnetic fields, Bioelectromagtnetics, vol. 13(Suppl. 1), pp. 27-42, 1992.

[16] MAALEJ, N. M. - BELHADJ, C. A.: External and internal electromagnetic exposure of workers near high voltage power lines, Progress in Electromagnetic Research C, Vol. 19, pp. 191-205, 2011.

[17] Department for Transport, Energy and Infrastructure, Government of South Australia, Building Safely near Power Lines, June 2007.

[18] National grid, Warwick, Development near Overhead Lines. Planning and Amenity Aspects of High Voltage Electricity Transmission Lines and Substations, July 2008.

[19] DRAPER, G. - VINCENT, T. - KROLL, M. E. SWANSON, J.: Childhood cancer in relation to distance from high voltage power lines in England and Wales: a case-control study, $B M J$, vol. 330, pp. 1-5, June 2005.

[20] AUGER, N - PARK, A. L. - YACOUBA, S. GONEAU, M. - ZAYED, J.: Stillbirth and residential proximity to extremely low frequency power transmission lines: a retrospective cohort study, Occupational and environmental medicine, vol. 69(2), pp. 147-149, 8 Jul 2011.

[21] HUSS, A. - SPOERRI, A - EGGER, M - ROOSLI, M., for the swiss national cohort study.: Residence near power lines and mortality from neurodegenerative diseases: longitudinal study of the swiss population, Am J Epidemiol, vol. 169, pp. 167$175,2009$.

[22] Department of Health Republic of South Africa, Limits for human exposure to time-varying electric, magnetic, and electromagnetic fields (up to 300 Ghz), Jan. 2002.

[23] Gigahertz Solutions, Dual function Gauss/Tesla meter for $\mathrm{AC}$ electric and $\mathrm{AC}$ magnetic fields - ME 3830B, available from www.gigahertzsolutions.com.

[24] OZEN, S. - COMLEKCI, S. - CEREZCI, O.: An evaluation for coupling of human to magnetic fields in human ellipsoidal models with frequency up to $100 \mathrm{kHz}$, Proceedings - 23rd Annual Conference IEEE/EMBS, Istanbul, Turkey, Oct 25-28, 2001.

[25] BORNER, F. - BRUGGEMEYER, H. - EGGERT, S. - FISCHER, M. - HEINRICH, H. HENTSCHEL, K. - NEUSCHULZ, H.: Electromagnetic fields at workplaces, A new scientific approach to occupational health and safety, Federal ministry of labour and social affairs, pp. 23, Nov. 2011.

[26] FALCK, E. - KEIKKO, T. - ISOKORPI, J. KORPINEN, L.: Application of geometrical models in the evaluation of health effects of transmission line electric and magnetic fields, The IASTED (the International Association of Science and Technology for Development) International Conference on applied modeling and simulation, Honolulu, Hawaii, USA, 1998.

Received April 4, 2014 , accepted June 9, 2014

\section{BIOGRAPHIES}

G. A. Kulkarni obtained his B.E. and M.E. from Government College of Engineering Aurangabad, Maharashtra. He has more than decade of teaching experience. Presently, he is working as an Associate Professor and Head of the department in Electronics \& Communication Engineering at Shri Sant Gadge Baba College of Engineering \& Technology, Bhusawal, Maharashtra, India. $\mathrm{He}$ is the life member of Indian Society for Technical Education.

Dr. W. Z. Gandhare obtained his Ph.D. from IIT Mumbai. Presently he is working as a principal in Government College of Engineering, Amravati. Published 95 papers in international/national journals \& Conferences. He is recognized Ph.D. guide at Shivaji University, Nagpur University, Dr. Babasaheb Ambedkar Marathwada University \& Govt. Engg. College, Aurangabad. He has been on various committees like AICTE, NBA and Dr. BATU, Lonere appointed by Hon. Governor of Maharashtra. He is best teacher awardee by Govt. of Maharashtra, India. 